\title{
Spermatic Cord Lymphoma: A Case Report and Literature Review
}

\author{
Satoru Taguchi, ${ }^{1,2}$ Sayuri Takahashi, ${ }^{1,2}$ Katsuyuki Iida, ${ }^{1}$ \\ Takashi Mizutani, ${ }^{1,2}$ Kazumi Yamaguchi, ${ }^{1}$ Takashi Tominaga, ${ }^{1,2}$ Naoya Niwa, ${ }^{3}$ \\ Mayumi Yoshimi, ${ }^{3}$ Tsuyoshi Takahashi, ${ }^{3}$ and Yukio Homma ${ }^{2}$ \\ ${ }^{1}$ The Department of Urology, Mitsui Memorial Hospital, Tokyo 101-8643, Japan \\ ${ }^{2}$ The Department of Urology, Faculty of Medicine, The University of Tokyo, Tokyo 113-8655, Japan \\ ${ }^{3}$ The Department of Hematology, Mitsui Memorial Hospital, Tokyo 101-8643, Japan
}

Correspondence should be addressed to Satoru Taguchi, satorutaguchi33@gmail.com

Received 17 September 2011; Accepted 1 November 2011

Academic Editor: Mark E. Shaffrey

Copyright (C) 2012 Satoru Taguchi et al. This is an open access article distributed under the Creative Commons Attribution License, which permits unrestricted use, distribution, and reproduction in any medium, provided the original work is properly cited.

\begin{abstract}
Spermatic cord lymphoma is a rare lethal disease. It has a poor prognosis even in stage I or II disease when treated locally, therefore, multidisciplinary treatment for early stage is recommended. On the other hand, the treatment of choice for stage III or IV spermatic cord lymphoma remains to be determined. It is said that spermatic cord lymphoma is clinicopathologically similar to primary testicular lymphoma, therefore the treatment of spermatic cord lymphoma has often been determined by reference to the recommended treatment for primary testicular lymphoma. Here we report a new case of spermatic cord lymphoma, which was found in stage IV disease. We also review thirty-three cases which have been reported as spermatic cord lymphoma to date, and discuss treatment options.
\end{abstract}

\section{Introduction}

Spermatic cord lymphoma is a rare lethal disease. To our knowledge, searching both English and Japanese literature, only thirty-three cases including our case have been reported [1-8]. It has a poor prognosis even in stage I disease when treated locally, therefore, multidisciplinary treatment for early stage is recommended. Here we report a new case of spermatic cord lymphoma, which was found in stage IV disease. We also review literature and discuss treatment options.

\section{Case Report}

In July 2010, a 62-year-old man visited an urologist with a complaint of a left intrascrotal mass and was placed under clinical observation without treatment. Two months later, a swelling of the right tonsil appeared, and he visited an otorhinolaryngologist. After a biopsy of the right tonsil, he was diagnosed with diffuse large B-cell lymphoma (DLBCL) and was admitted to our hospital. Physical examination showed that the right tonsil swelled up beyond the midline, right cervical and left supraclavian lymph nodes were palpable, and a 50-mm mass existed along the left spermatic cord. $\mathrm{He}$ also had night sweats. In the blood examination, high levels of serum soluble interleukin-2 receptor were detected $(5290 \mathrm{U} / \mathrm{mL})$. Ultrasonography showed a $50 \mathrm{~mm}$ tumorous lesion in maximum diameter in the left spermatic cord and a $5 \mathrm{~mm}$ mass in the right spermatic cord, respectively. Computed tomographic scan (CT) showed the swelling of the right tonsil and the enlargement of right cervical, left supraclavian, and para-aortic lymph nodes. $67 \mathrm{Ga}$ scintigraphy showed intense uptake in the same lesions which were detected in CT, but no uptake in groins (Figure 1). Bone marrow aspiration showed a few large atypical cells that were positive for $\mathrm{CD} 20$ and negative for $\mathrm{CD} 3$, which suggests the invasion of lymphoma to the bone marrow. Based on these findings, he was clinically diagnosed as DLBCL at stage IVB (Ann Arbor Staging). In December 2010, he underwent left radical orchiectomy for confirming the diagnosis and mass reduction. Macroscopically, a white $67 \mathrm{~mm}$ tumor in maximum diameter existed around the left spermatic cord, but the testis and the epididymis were not involved (Figure 2). It consisted of proliferative large atypical lymphocytes (Figure 3). Immunohistochemistry revealed that the 

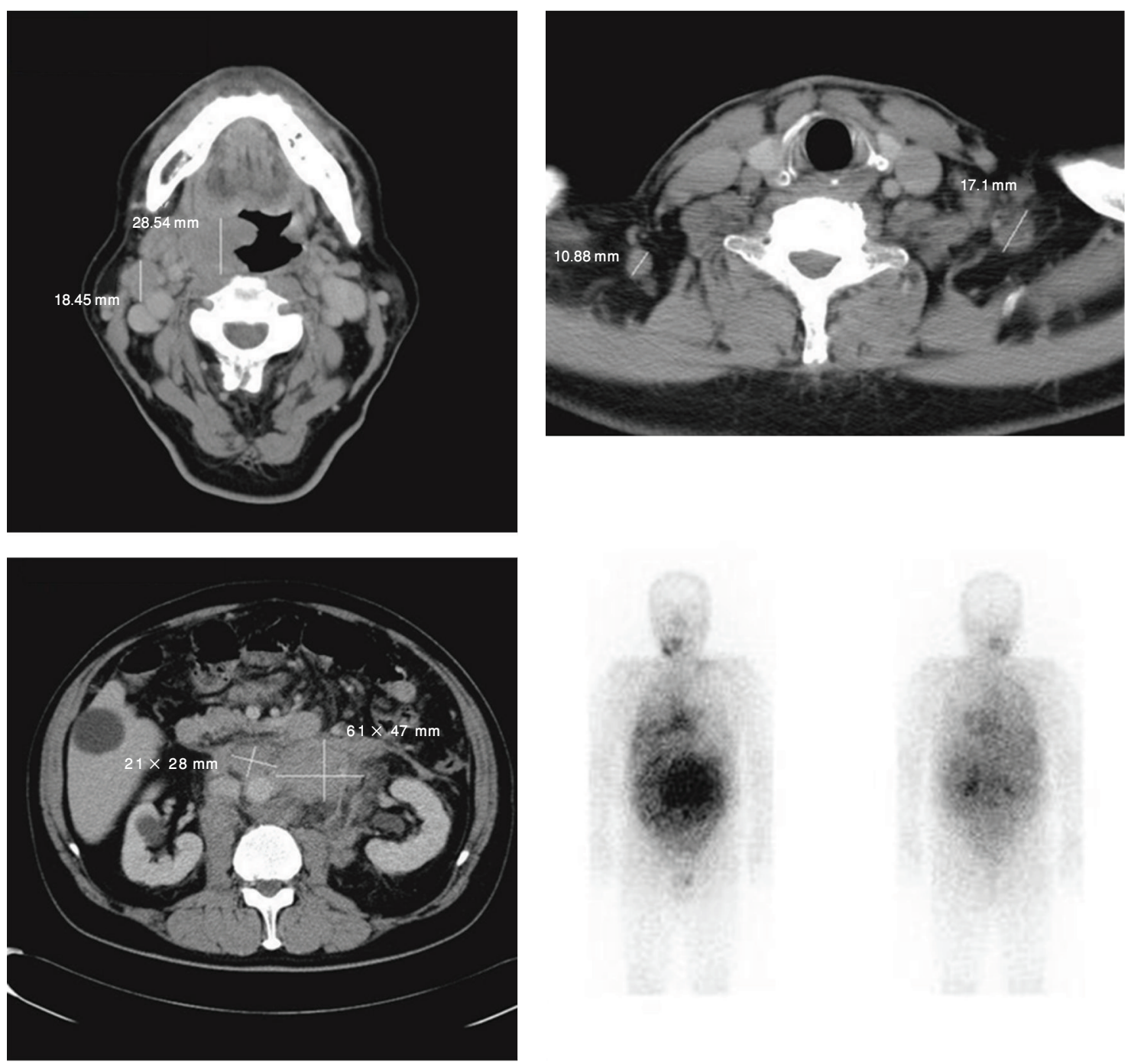

FIGURE 1: Computed tomographic scan (CT) showing the swelling of the right tonsil and the enlargement of right cervical, left supraclavian, and para-aortic lymph nodes. $67 \mathrm{Ga}$ scintigraphy showing intense uptake in the same lesions which were detected in CT.

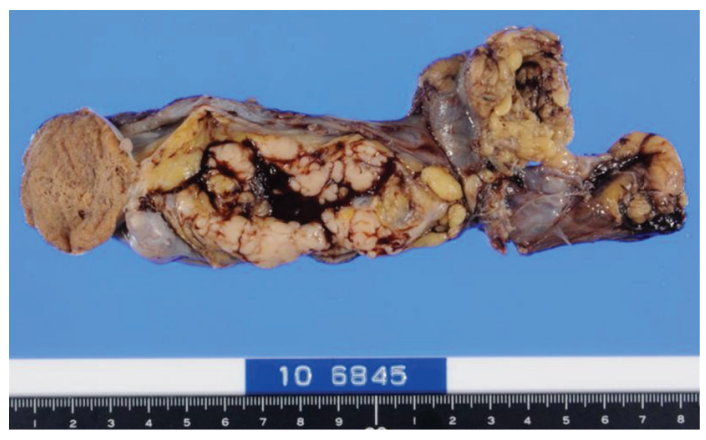

FIGURE 2: Gross appearance of the surgical specimen showing a white $67 \mathrm{~mm}$ tumor around the left spermatic cord.

tumor cells were positive for CD20 and negative for CD3. Histopathological diagnosis was DLBCL of the left spermatic cord. As adjuvant therapy, he completed both 6 cycles

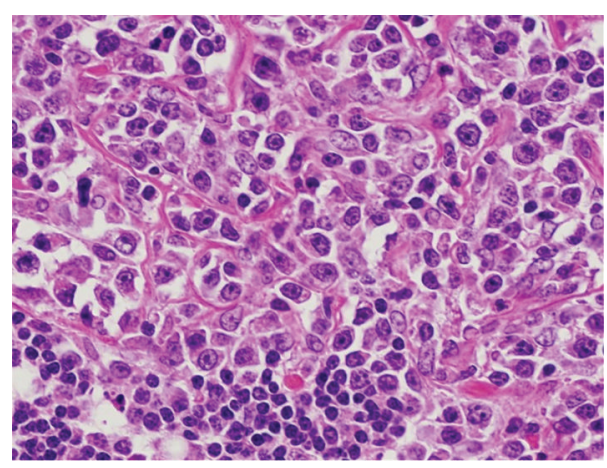

FIgURE 3: Microscopic features of the tumor consisting of proliferative large atypical lymphocytes.

of rituximab added to cyclophosphamide, doxorubicin, vincristine, and prednisone (R-CHOP) and 4 cycles of intrathecal methotrexate (IT-MTX) for central nervous system 
TABLE 1: Reported cases of spermatic cord lymphoma.

\begin{tabular}{|c|c|c|c|c|c|c|c|}
\hline & Author & Age, $y$ & Stage & Histology & Immuno-phenotype & $\begin{array}{c}\text { Initial } \\
\text { treatment }\end{array}$ & Survival, mo \\
\hline 1934 & Fresnais & 73 & IE & LS & NA & $\mathrm{O}$ & DOD, 5 \\
\hline 1936 & Slotkin & 36 & $\mathrm{IE}$ & LS & NA & $\mathrm{O}$ & DOD, 1 \\
\hline 1949 & Hector & 64 & IE & RES & NA & $\mathrm{O}$ & DOD, 62 \\
\hline 1954 & Wetterwald & 49 & IIE & LB & NA & $\mathrm{O}$ & DOD, 1 \\
\hline 1957 & Pelot & 21 & IE & RS & NA & $\mathrm{O}, \mathrm{RT}$ & DOD, 12 \\
\hline 1970 & Bologna & 42 & IE & LRS & NA & $\mathrm{O}, \mathrm{RT}$ & DOD, 6 \\
\hline 1970 & Gotou & 57 & IE & RS & NA & $\mathrm{O}, \mathrm{RT}$ & NA \\
\hline 1972 & Iwata & 30 & IIE & LS & NA & $\mathrm{O}, \mathrm{CT}$ & DOD, 3 \\
\hline 1972 & Katou & 75 & III & RS & NA & $\mathrm{O}, \mathrm{CT}$ & DOD, 3 \\
\hline 1980 & Karapandov & 57 & $\mathrm{IE}$ & $\mathrm{CB} / \mathrm{CC}$ & NA & $\mathrm{O}, \mathrm{RT}$ & NA \\
\hline 1982 & Guena & 46 & IE & $\mathrm{CB} / \mathrm{CC}$ & NA & NA & NA \\
\hline 1982 & Satou & 49 & IE & Burkitt & B & $\mathrm{O}, \mathrm{CT}$ & NA \\
\hline 1986 & Hautzer & 54 & IE & CBD & NA & $\mathrm{O}$ & DOD, 7 \\
\hline 1986 & Hanada & 74 & IE & DLC & NA & $\mathrm{O}$ & DOD, 5 \\
\hline 1989 & Zwanger-Mendelson & 20 & IV & Burkitt & B & $\mathrm{O}$ & DOD, 1 \\
\hline 1989 & Ooyama & 66 & IIE & DLC & NA & $\mathrm{O}, \mathrm{CT}$ & NA \\
\hline 1990 & D’Abrosca & 89 & IE & CBD & NA & NA & DOD, NA \\
\hline 1990 & Nishimura & 47 & IIE & DLC & NA & $\mathrm{O}, \mathrm{CT}$ & NA \\
\hline 1994 & Möller & 48 & IV & $\mathrm{CBD}$ & B & NA & DOD, 8 \\
\hline 1994 & Kawanishi & 66 & IE & DMC & NA & $\mathrm{O}, \mathrm{CT}, \mathrm{RT}$ & NA \\
\hline 1994 & Asanuma & 78 & IE & DLC & NA & CT & NA \\
\hline 1994 & Oonishi & 76 & IE & DMC & NA & $\mathrm{O}$ & NA \\
\hline 1996 & Lands & 57 & IE & DLC & $\mathrm{B}$ & $\mathrm{O}$ & DOD, 26 \\
\hline 1997 & Umehara & 78 & IE & DLC & NA & $\mathrm{O}$ & NA \\
\hline 1998 & Ichiyanagi & 77 & IIE & DLC & $\mathrm{B}$ & $\mathrm{O}, \mathrm{CT}$ & DOD, 10 \\
\hline 2001 & Okabe & 76 & IE & DMC & $\mathrm{B}$ & $\mathrm{O}$ & DOD, 40 \\
\hline 2007 & Kawano & 57 & IIE & DLBCL & $\mathrm{B}$ & $\mathrm{O}, \mathrm{CT}$ & NA \\
\hline 2008 & Nakano & 54 & IVA & DLBCL & B & $\mathrm{O}, \mathrm{CT}$ & DOD, 5 \\
\hline 2009 & Natsuizaka & 75 & $\mathrm{IE}$ & DLBCL & B & $\mathrm{O}, \mathrm{CT}$ & NA \\
\hline 2009 & Almeida & 71 & IE & DLBCL & B & $\mathrm{O}, \mathrm{CT}$ & NA \\
\hline 2009 & Suzuki & 74 & IIIA & DLBCL & B & $\mathrm{O}, \mathrm{CT}$ & DOD, 13 \\
\hline 2009 & Asano & 71 & IE & DLBCL & B & $\mathrm{O}, \mathrm{CT}$ & NA \\
\hline 2011 & Our case & 62 & IVB & DLBCL & $\mathrm{B}$ & O, CT, RT, IT & NA \\
\hline
\end{tabular}

O, orchiectomy; CT, chemotherapy; RT, radiotherapy; IT, intrathecal chemotherapy; CBD, centroblastic diffuse; CB/CC, centroblastic/centrocytic; LB, lymphoblastic; LS, lymphosarcoma; RS, reticulosarcoma; LRS, lymphoreticulosarcoma; RES, reticuloendotheliosarcoma; DLC, diffuse large cell; DMC, diffuse medium cell; DLBCL, diffuse large B-cell lymphoma; mo, months; NA, not available; DOD, died of disease.

(CNS) prophylaxis. Then, he also underwent radiotherapy (RT) to the right testis for prophylaxis of contralateral testicular relapse. CT performed 4 months after the orchiectomy showed that all lesions either disappeared or reduced, and that there was no new lesions.

\section{Discussion}

Male gonadal involvement is relatively uncommon in malignant lymphoma. Of these lymphomas, testicular lympho$\mathrm{ma}$ is the most frequent, accounting about $1 \%$ of all nonHodgkin's lymphomas [9]. On the other hand, spermatic cord lymphoma is very rare, and to the best of our know- ledge, only thirty-three cases including our own case have been reported (Table 1) [1-8]. The patients ranged in age from 20 to 89 years (mean age, 60-year-old). Middle-aged men (14 out of 33 cases) and older men (15 out of 33 cases) were mainly affected [10]. Most cases were stage I disease at the time of diagnosis (stage I, 21 cases; stage II, 6 cases; stage III, 2 cases; stage IV, 4 cases), nevertheless, they apparently have a poor prognosis (median survival, 12.2 months). Our case was already in stage IV at presentation. In general, it is difficult to detect the primary site when a patient with malignant lymphoma has multiple lesions. However, the first manifestation of our case was the spermatic cord tumor. Spermatic cord lymphoma has a tendency to 
spread or relapse towards para-aortic lymph nodes, while lymphomas derived from different primary lesions hardly metastasize to a spermatic cord in an early stage [5]. Therefore, we assumed the primary site in our case might be the spermatic cord. Histologically reviewing, intermediate-grade lymphomas (Working Formulation), centroblast or centroblastic-centrocytic lymphomas (Kiel classification), and DLBCL (WHO classification) were most frequently observed, except two cases which suffered from Burkitt's subtype [1, 4]. All cases that the immunophenotypical study was performed showed a B-cell phenotype.

It is said that spermatic cord lymphoma is clinicopathologically similar to primary testicular lymphoma (PTL). PTL is a potentially fatal disease second only to primary brain lymphoma; median survival is between 12 and 24 months [9]. It is due to failures in contralateral testis, CNS, and extranodal sites. Recently, an international phase II trial showed that the recommended first-line treatment for stage I or II PTL is orchiectomy followed by R-CHOP, IT-MTX, and RT to the contralateral testis [10]. In the same way, it has been said that multidisciplinary treatments should be given in early staged spermatic cord lymphoma, but actually was not. Reviewing reported cases of stage I spermatic cord lymphoma, the initial treatment was only orchiectomy with or without RT by the 1980s, and the ratio of combining chemotherapy or not has become half and half since the 1990s. No case except ours underwent IT-MTX. Median survival of stage I spermatic cord lymphoma treated only orchiectomy with or without RT was 18.2 months, while 5-year overall survival rates of early staged PTL treated multidisciplinarily were $85 \%$ in the recent trial [10]. It suggests that combined treatment with R-CHOP, IT-MTX, and RT to the contralateral testis will attribute a better outcome in early staged spermatic cord lymphoma.

On the other hand, the treatment of choice for stage III or IV disease in spermatic cord lymphoma still remains to be determined. For advanced PTL, the recommended first-line treatment is R-CHOP, however a median survival of less than six months is reported [9]. Despite a higher rate of relapse in the contralateral testis (up to $50 \%$ of patients), RT to the contralateral testis is recommended by some authors, while others propose RT only for symptomatic patients or in the case of bulky disease. IT-MTX to prevent CNS relapse, which occurs in approximately $50 \%$ of patients, is also considered in patients achieving complete remission.

\section{References}

[1] S. Zwanger-Mendelsohn, E. H. Shreck, and V. Doshi, "Burkitt lymphoma involving the epididymis and spermatic cord: sonographic and CT findings," American Journal of Roentgenology, vol. 153, no. 1, pp. 85-86, 1989.

[2] F. D’Abrosca, M. Lucev, V. Turi, E. Gerosa, and L. Villani, "Primary malignant lymphoma of the spermatic cord," Minerva Chirurgica, vol. 45, no. 7, pp. 531-533, 1990.

[3] M. B. Moller, "Non Hodgkin's lymphoma of the spermatic cord," Acta Haematologica, vol. 91, no. 2, pp. 70-72, 1994.

[4] R. H. Lands, "Non-Hodgkin's lymphoma originating in the spermatic cord," Southern Medical Journal, vol. 89, no. 3, pp. 352-353, 1996.
[5] N. Ichiyanagi and T. Matsumura, "Non-Hodgkin's lymphoma of the spermatic cord: a case report," Hinyoukika Kiyo, vol. 44, no. 6, pp. 427-429, 1998.

[6] M. Okabe and M. Kurosawa, "Primary lymphoma of spermatic cord," Leukemia and Lymphoma, vol. 40, no. 5-6, pp. 663-666, 2001.

[7] M. Natsuizaka, M. Kudo, M. Suzuki et al., "Diffuse large Bcell lymphoma with massive portal vein tumor thrombosis in a patient with alcoholic cirrhosis: a case report and literature review," Internal Medicine, vol. 48, no. 10, pp. 805-808, 2009.

[8] M. W. R. Almeida and A. B. S. Diniz, "Non-Hodgkin's lymphoma of the spermatic cord," Revista do Colegio Brasileiro de Cirurgioes, vol. 36, no. 5, pp. 466-467, 2009.

[9] A. Zouhair, E. Herrmann, G. Ugurluer, P. M. Gaye, R. O. Mirimanoff, and M. Ozsahin, "Primary testicular lymphoma," Swiss Medical Weekly, vol. 140, Article ID W13076, pp. 25-28, 2010.

[10] U. Vitolo, A. Chiappella, A. J. M. Ferreri et al., "First-line treatment for primary testicular diffuse large B-cell lymphoma with rituximab-CHOP, CNS prophylaxis, and contralateral testis irradiation: final results of an international phase II trial," Journal of Clinical Oncology, vol. 29, no. 20, pp. 27662772, 2011. 


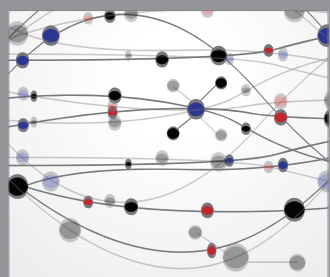

The Scientific World Journal
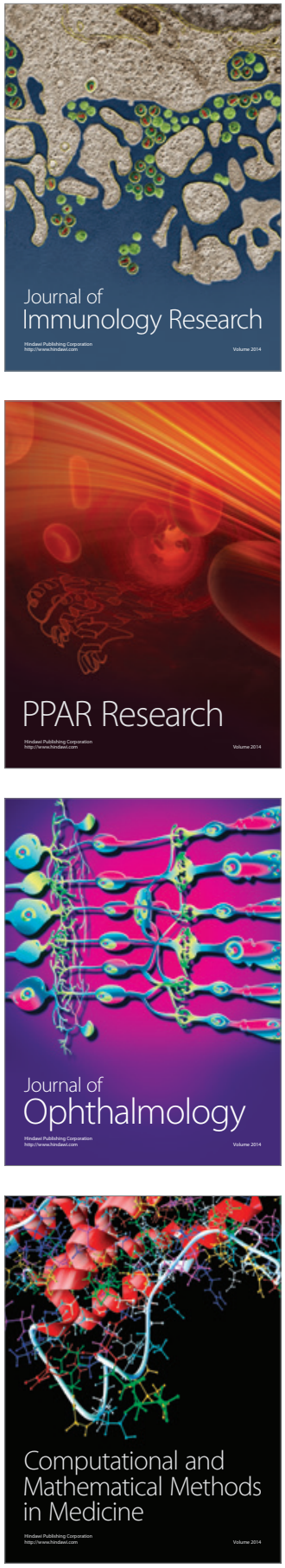

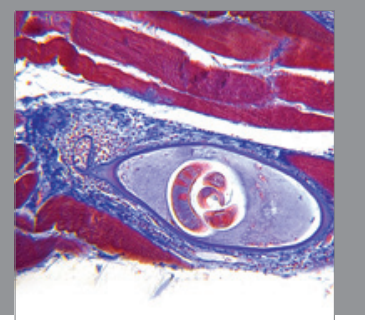

Gastroenterology

Research and Practice
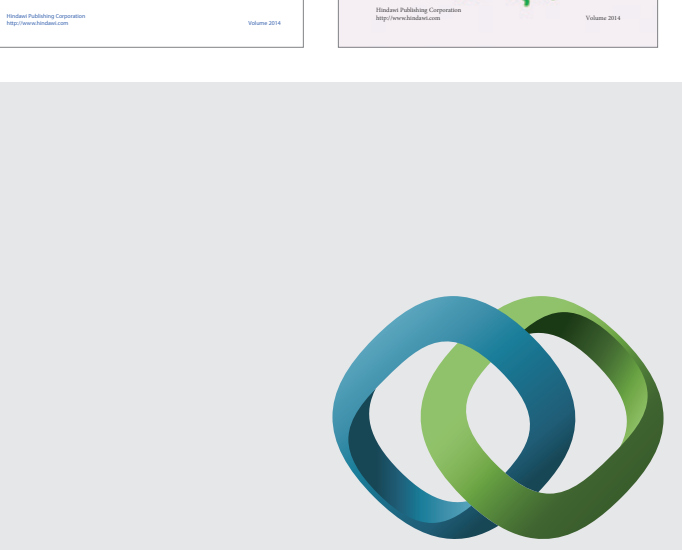

\section{Hindawi}

Submit your manuscripts at

http://www.hindawi.com
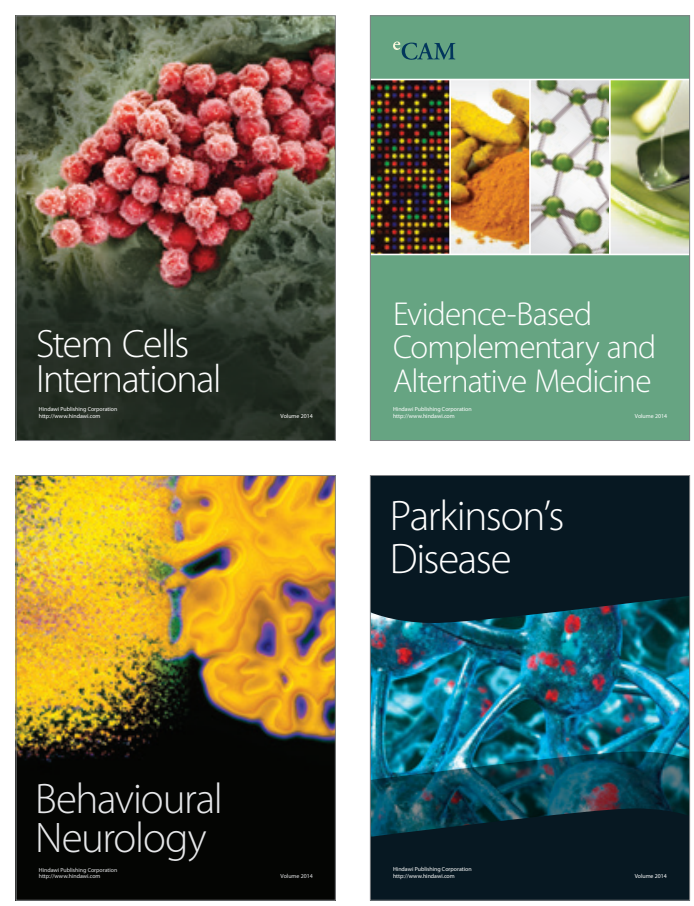

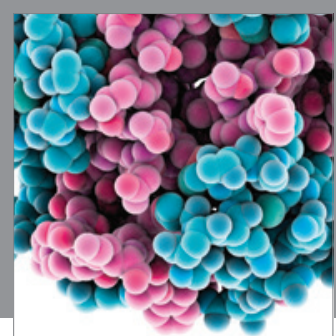

Journal of
Diabetes Research

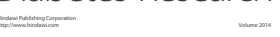

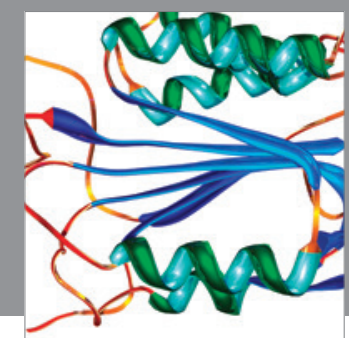

Disease Markers
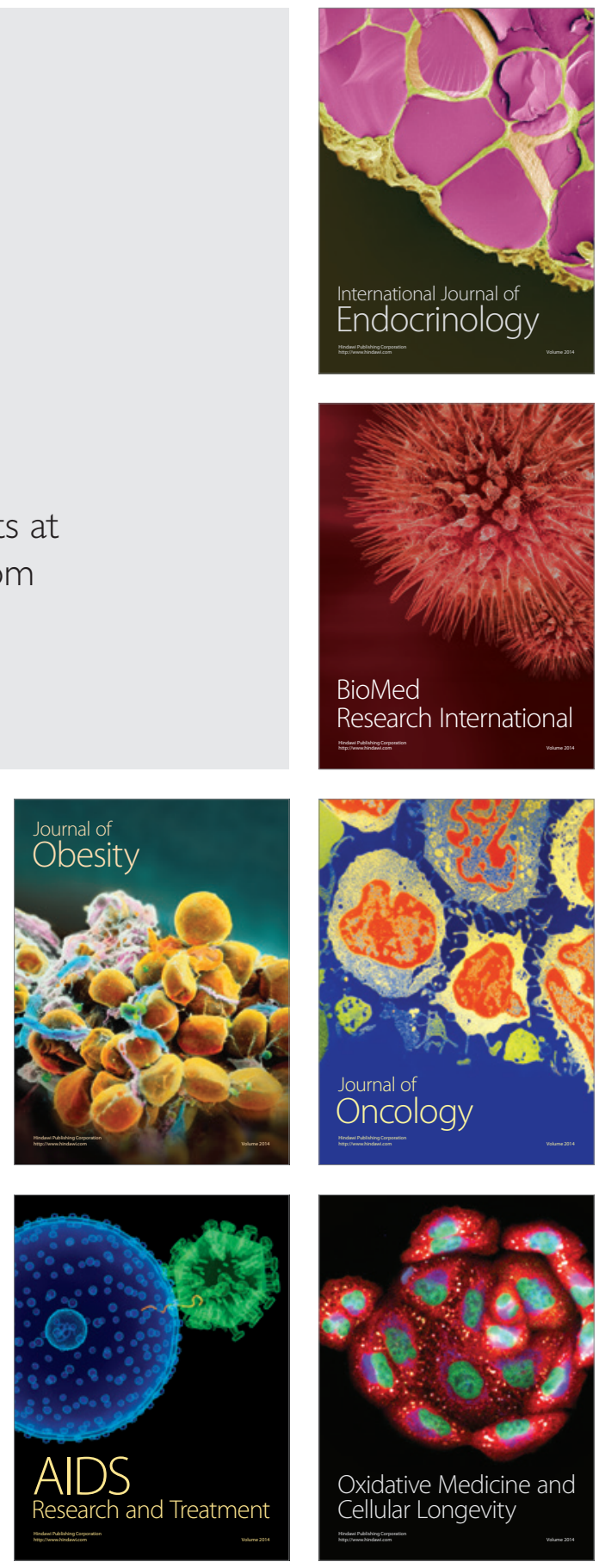